Center for Pharmaceutical Policy and Prescribing, University of Pittsburgh School of Medicine, Pittsburgh, PA, USA

Walid.gellad@pitt.edu

Cite this as: BMJ 2021;375:n3090 http://dx.doi.org/10.1136/bmj.n3090 Published: 16 December 2021

\section{Myocarditis after vaccination against covid-19}

\author{
Data from Denmark indicate low risk, with important differences between vaccines \\ Walid F Gellad professor of medicine and director
}

The mRNA vaccines from Pfizer-BioNTech (BNT162b2) and Moderna (mRNA-1273) are a stunning success of science. They have saved countless lives and have a demonstrated safety record in a billion administered doses worldwide. No drug in history, however, has been completely free of adverse events. Myocarditis, although rare, is a known side effect of the mRNA vaccines and has been a barrier to uptake primarily because of uncertainty around its severity and frequency. Much of the pharmacovigilance data identifying myocarditis has been from passive reports and could be incomplete. There have also been a handful of case reports. What has been missing are complete population based studies that can give a less biased assessment of incidence.

It is in this context that the linked study by Husby and colleagues (doi:10.1136/bmj-2021-068665) is considered. ${ }^{1}$ These authors reviewed data from all five million residents of Denmark age 12 and older, four million of whom received one of the mRNA vaccines from October 2020 to October 2021. They identified all cases of myocarditis or myopericarditis, defined as a hospital diagnosis of myocarditis or pericarditis plus an increased troponin level and admission lasting $>24$ hours. The primary analysis used a cox proportional hazards model to compare the risks of myocarditis or myopericarditis 28 days after vaccination with risk during unvaccinated time. The authors also performed a nested self-controlled case series to deal with confounding, and they got similar results.

The study confirms what is already known about vaccine associated myocarditis-that it is rare, but it exists. Of 3.5 million people who received BNT162b2, 48 developed myocarditis or myopericarditis within 28 days (54\% male, $56 \%$ second dose), giving an incidence of 1.4 per 100 ooo vaccinated individuals. The increased rate of myocarditis or myopericarditis was not statistically significant in the primary analysis (adjusted hazard ratio 1.34, 95\% confidence interval 0.90 to 2.00), although it was statistically significant in an analysis using a 14 day post-exposure window (1.89, 1.23 to 2.90$)$. In perhaps the most surprising result, the vaccine was associated with myocarditis or myopericarditis only in female, not male, participants. That just under half of the cases were in female participants and after the first dose is unexpected, inconsistent with international data, and hard to explain.

Results for Moderna's vaccine mRNA-1273 are more consistent with previous studies: of 500 ooo people vaccinated, 21 developed myocarditis or myopericarditis ( $76 \%$ male, $86 \%$ second dose), giving an overall incidence of 4.2 per 100 ooo. Risk was increased in both male and female participants (adjusted hazard ratio 3.92, 2.30 to 6.78), with substantially higher risk after the second dose.

Overall, the rate of vaccine associated myocarditis or myopericarditis in Denmark is lower than the rate reported in other settings, although it is difficult to compare across settings given differences in case definition and population characteristics. For example, among 5.1 million Israelis vaccinated with BNT162b2, 136 cases of myocarditis occurred within 21 days, or an overall rate of 2.7 per 100 ooo, compared with 1.4 per 100000 in Denmark. ${ }^{2}$ Age differences could be at play, but even in the youngest groups the rates in Denmark are lower than those elsewhere. In young people aged 12-17 years (boys and girls combined), the rate of myocarditis or myopericarditis in Denmark was 1 per 100000 with BNT162b2 compared with 18.5 per 100 ooo in Hong Kong, ${ }^{3}$ and roughly 7 per 100 ooo in Israel (ages 16-19 years). ${ }^{2}$ In 12-39 year old males after the second dose of BNT162b2, the incidence of myocarditis or myopericarditis in Denmark was only 1.8 per 100 ooo, compared with $>7$ per 100 ooo in 16-39 year old males in Israel. ${ }^{2}$

Why might the rates of vaccine associated myocarditis or myopericarditis seem lower in Denmark? Clearly the definition of myocarditis will influence the reported incidence. Husby and colleagues' case definition was strict, requiring a hospital stay of at least 24 hours combined with an increased troponin level. Differences in surveillance for adverse effects could also play a role, as could differences in vaccine dosing interval. In Denmark, the median time between BNT162b2 doses was five weeks, longer than the three weeks recommended in Israel and the United States. The authors offer this longer dosing interval as one potential explanation for the lower rates of myocarditis or myopericarditis in Denmark. This hypothesis has support. Researchers from Canada recently found a lower rate of myocarditis associated with longer spacing between doses. ${ }^{4}$ In the United Kingdom, which also extended time between doses, the rate of myocarditis after vaccination with BNT162b2 appears similarly low, at 1 per 100000.5

Husby and colleagues also confirm a higher rate of myocarditis or myopericarditis with mRNA-1273 compared with BNT162b2. Among men younger than 40, the incidence of myocarditis associated with mRNA-1273 was five times higher than the incidence associated with BNT162 b2 (9.4 v. 1.8 per 100 0oo). This finding has been confirmed in the US, ${ }^{6}$ Canada, 4 Japan, ${ }^{7}$ Germany, ${ }^{8}$ France, ${ }^{9}$ and in other Nordic countries. Those countries, unlike the US, have decided to recommend BNT162b2 over mRNA-1273 for young people. 
The mRNA vaccines against covid-19 are remarkably effective and provide tremendous benefit to recipients. The risks of myocarditis or myopericarditis are low and must be balanced against these many benefits. Balancing risks and benefits, however, means measuring risks accurately, and population based studies such as this one are vital for ensuring this proper balancing, and for identifying ways to maintain the benefits of vaccination while reducing the risks.

Competing interests: The BMJ has judged that there are no disqualifying financial ties to commercial companies. The authors declare the following other interests: None.

Further details of The BMJ policy on financial interests is here: https:/www.bmj.com/sites/default/files/attachments/resources/2016/03/16-current-bmj-education-coi-form.pdf.

Provenance and peer review: Commissioned; not externally peer reviewed.

1 Husby A, Hansen JV, Fosbol E, etal. SARS-CoV-2 vaccination and myocarditis or myopericarditis: population based cohort study. BM/2021;375:e068665.

2 Mevorach D, Anis E, Cedar N, etal. Myocarditis after BNT162b2 mRNA Vaccine against Covid-19 in Israel. N Engl / Med 2021;385:2140-9. doi: 10.1056/NEJMoa2109730 pmid: 34614328

3 Chua GT, Kwan MYW, Chui CSL, etal. Epidemiology of Acute Myocarditis/Pericarditis in Hong Kong Adolescents Following Comirnaty Vaccination. Clin Infect Dis 2021;ciab989. doi: 10.1093/cid/ciab989 pmid: 34849657

4 Buchan SA, Seo CY, Johnson C, et al. Epidemiology of myocarditis and pericarditis following mRNA vaccines in Ontario, Canada: by vaccine product, schedule and interval. MedRxiv. Preprint. www.medrxiv.org/content/10.1101/2021.12.02.21267156v1. (Accessed 10 Dec 2021.) doi: $10.1101 / 2021.12 .02 .21267156$

5 UK Medicines and Healthcare products Regulatory Agency. Coronavirus vaccine - weekly summary of yellow card reporting. www.gov.uk/government/publications/coronavirus-covid-19-vaccineadverse-reactions/coronavirus-vaccine-summary-of-yellow-card-reporting. (Accessed $10 \mathrm{Dec}$ 2021.)

$6 \quad$ Klein N. Myocarditis Analyses in the Vaccine Safety Datalink: Rapid Cycle Analyses and "Head-to-Head" Product Comparisons. Presentation at the Advisory Committee on Immunization Practices (ACIP) October 20, 2021. www.cdc.gov/vaccines/acip/meetings/slides-2021-10-2021.html. (Accessed 10 Dec 2021.)

7 NHK- Japan. Health ministry warns of vaccine's side effects. December 4, 2021. www3.nhk.or.jp/nhkworld/en/news/20211204_12/. (Accessed 10 Dec 2021.)

8 Alkhousaa R. Germany recommends only Biontech/Pfizer vaccine for under-30s. Reuters. November 10, 2021. www.reuters.com/world/europe/germany-recommends-only-biontechpfizervaccine-people-under-30-2021-11-10/. (Accessed 10 Dec 2021.)

9 Reuters. French health authority advises against Moderna COVID-19 vaccine for under 30s. November 9, 2021. www.reuters.com/business/healthcare-pharmaceuticals/french-health-authority-advises-against-moderna-covid-19-vaccine-under-30s-2021-11-09/. (Accessed 10 Dec 2021.)

This article is made freely available for use in accordance with BMJ's website terms and conditions for the duration of the covid-19 pandemic or until otherwise determined by BMJ. You may use, download and print the article for any lawful, non-commercial purpose (including text and data mining) provided that all copyright notices and trade marks are retained. 